\section{CAUSES OF HEPATIC DISEASES IN THE EAST TNDIES.}

By SIR J. RANALD MARTIN, C.B., F.R.S., PHYSICIAN TO THE CODNCIL OF INDIA.

OF all the causes which tend to the production of hepatic diseases in the East Indies, peculiar climatic influences, acting on race, are the greatest-climatic influences which do not exist, or which exist in a very minor degree, in other hot countries. That the prevalence of malarious fevers and dysenteries, the absence of wholesome exercises, the confinement in over-crowded and ill-ventilated barracks, along with the abuse of animal food and alcoholic drinks, the undue exposume to heat, cold, damp, and other external causes, give a fearfully additional power and prevalence to attacks of those diseases in India, cannot be denied. But in estimating the extent of such influences in the East, as compared with other warm climates, it must be recollected that the ages, habits of life, duties, and occupations of British soldiers are the same in the West as in the East Indies; yet in the Windward and Leeward command the cases of hepatic diseases are but $2 \cdot 24$ per cent., as compared with 6.2 in Bengal, 7.93 in Bombay, and 8.92 in Madras. The differences in the effects of climate are here presented as facts, but the essential nature of the difference is not physiologically ascertained. The effects of high temperature and of the rarefaction of the air on respiration and on the hepatic functions I do not here discuss, as they are common to the West as to the East Indies.

If, on the other hand, chronic interstitial inflammation of the liver, or interlobular hepatitis, terminating in cirrhosis, be a common or chief result, in temperate climates, of the abuse of ardent spirits, as stated by Frerichs and by all modern writers, what must be the effects of such habitual abuse under a climate such as that of the East Indies, and under the defective sanitary arrangements existing there, in respect of the European soldier!

"The entrance into the portal vein," says Frerichs, "of colourless corpuscles, of pigment seales, and of various products of metamorphosis, in certain diseases of the spleen, the effects upon the liver of different matters which find their way into the portal blood during digestion, together with many other circumstances affecting the circulation, innervation, and secretion in the portal system, are subjects which afford an ample field for investigation in connexion with this subject."

Again :- "The rapid absorption of spirits from the stomach into the portal vein must, in the first place, give rise to irritation of the liver, which after a time subsides, the more that the absorbed fluid becomes mixed with the entire mass of the blood, and evaporated through the lungs. After poisoning animals with alcohol, Perez found the largest quantity of alcohol in the liver."

For a hundred years we have fed, clothed, housed, and disciplined our British troops in India on the Prussian model of George the Second's time; and who shall count the united influences and consequences since then of the "fire-water" and of the "fire-shirt"* on the sickness and mortality of those troops? The "regulation" rum-ration and the "regulation" red jacket--very well in an English winter-are death in tropical climates. The fact is that, chiefly through our own mismanagement, we shall never know how far hepatic diseases in India are to be referred to climate alone, until we shall have weaned the British soldier from the baneful habit of spirit. drinking. Here, it must be admitted, the common sense of the natives of India has been far in advance of our ever-imitative regulation-mongers.

Of the progressive diminution of hepatitis, to be secured to us by improved habits and conditions of life, and by improved modes of medical treatment of malarions fevers and dysenteries especially, we may form some judgment from the facts stated by Dr. Ewart, of the Bengal Army. After presenting a table showing the sickness and mortality from hepatitis during the years from 1812 to 1854 , the author says:- "From this table it may be affirmed that during the most modern periods of observation there has been a palpable diminution of cases of liver disease, as compared to the remote periods, amounting to 96 in * The terms used for more than a hundred years by the natives of India to describe the "regulation" rum-ration and red turic of the European soldier.
Bengal, 43 in Bombay, and to 380 in Madras, out of 10,000 of strength. This gratifying result is partly due to the greater temperance of the European army in diet and drink, to their improved condition, and partly to our improved treatment of malarious fevers." The climatic or external causes of hepatitis and its sequelæ are-the peculiar climate of the regions of the East, acting on the stranger European; the absence in India of a temperate zone, and the continued application consequently of an unnatural heat; the counter influences of night chills, and of other alternations in the temperature and humidity of the atmosphere. When these come to be applied to the white man, -a subject prepared, as we have seen, by constitution and habit of life for their reception,-we perceive how powerful, in the East Indies, these effects must be. European females are far less prone to hepatic disease of every kind than males, and this is mainly owing to their greater temperance, and perhaps in some measure to their sex.

Prevention.-A just appreciation of the various causes of hepatic disease in the East will lead us far into a knowledge of the means necessary for their prevention; and the first of these will be found in the avoidance of the peculiar actions of the climate of the hot pestilential plains, the special seats of fever, dysentery, hepatitis, and cholera.

There is no separating the causes affecting European from such as influence native health; and the vicinity of swarming towns, bazaars, and the lines of native troops, has ever been, and must always be, seriously detrimental to the health and morals of the British soldiery, from their climate, their extremely defective sanitary condition, and from their containing such large numbers of natives of the lowest castes and most depraved classes of both sexes, ever ready to minister to the worst propensities of the soldier. In most of our stations throughout India it would be difficult to determine whether they derive more of their injurious influences from climate and defect of proper locality, or from the defiance which they present to all measures of medical police.

Were there no arguments other than those founded on such facts for securing immediate recourse to the pure cool atmosphere of the mountain ranges throughout India, surely they ought to suffice to determine the question in favour of the soldier. And even if over-feeding, the over-crowding in barracks, the fire-water and fire-shirt be his necessary lot, they will be made to lose more than half their venom in the European climates of the hill stations everywhere to be found in the East. * But it must be remembered that hill stations, even the best, must require culture of the soil and other labours to render them fully effective; indeed, no locality, however favoured, can be exempted from such necessary attentions. In sanitary affairs especially, error begets error, and we are not less injured by those we commit than by those we omit or give occasion to. To remedy the enormous evils consequent on the malposition of our European troops we must look alone to the Government-the only moving power in India ; for the natives, without such influential promptings, will do nothing, even in the places inhabited by themselves. The removal, therefore, of the British troops to other and better stations than those now generally occupied by them on the plains would seem im. perative, as an immediate duty to the army, if we are to arrest the present enormous rates of sickness and mortality in their ravks. Were the stations on the plains as healthy as they are notoriously the reverse, the time, labour, and cost of their sanitary improvement over the vast area of British India would be something inconceivably great; while, obviously, on the hill ranges, the time, labour, and cost required for improvement would be comparatively trifling. I am aware that the rum-ration and the red jacket are not in such open and avowed favour as formerly; but fancy in command may any day restore them.

Conclusions.-The native Hindoos do not suffer from hepatic diseases in any degree as compared to the European. This must be, lst, partly because the native population is acclimated, and proof against the malarious influences so pernicious to the European; and, 2nd, partly because of the extreme comparative temperance of the native population in all that relates to animal food and stimulating drinks.

The inference deducible from the foregoing remarks clearly is, that we should as far as practicable raise the Europeans in India above malarious influences by placing them in the cool mountain ranges; and that we should endeavour suitably to assimilate their condition to that of the native in all that relates to diet, clothing, exercise, \&c.

* The Psalmist prized his mountain at a high value: "He brought them within the borders of his sanctuary, even to his mountain which he purchased with bis right hand." 
Occupations and amusements for the European soldier are especially needed in hot climates, where during the hot and rainy seasons be is shut up during many months of the year. In that season the soldier is an absolute prisoner, the monotonous parade even being seldom practicable. He wearies in body and mind, and longs for the medicina mentis. When anything in this direction has been thought of throughout our foreign possessions, what little has been done has been by halves, by fits and starts, and with very little effect.

A curious problem is beginning its solution in India, the war between the Federal and Confederate States of America tending to force the cultivation of India by Enropean capital and enterprise in an extraordinary degree. This cultivation must tend to diminish malarious influences by purifying the soil, and thus effecting the greatest improvement in climate. Cotton, coffee, and tea are already being cultivated, and will prove of enormons sanitary importance in the future of India. Every square mile of jungle converted to the growth of crops useful to man, is pro tanto an improvement of the East in a sanitary point of view.

Mount-street, Grosvenor-square, May, 1863.

\section{ON A CASE OF AN ÆMIC SPHACELUS.}

\section{Bx A. S. MYRTLE, M.D., Harrogate.}

Coloner A. B , aged forty-six, five feet ten inches in height, healthy.looking, strongly built, and of sanguine tem. perament, consulted me on August 11th, 1862. He gave the following account of himself :-

"I have been twenty.two years in the army, and during the last seven was constantly engaged in active foreign service with my regiment. I spent three years in the West Indies, two years in the Crimea, and two in India. During these seven zears my work was hard and anxiety considerable; still I enjoyed uniform gord health, and felt quite equal to the perform. ance of my duties. I have always lived freely, and taken both beer and wine daily; I have spent much of my time in the open air, have had a good appetite, and slept well. At this present moment I never felt better in my life. My reason for applying to you for advice is, that for the last three or four mornings the fingers of both hands, more especially the right, have remained more or less dead after I get up; they feel cold and numb. My ears also experience a tingling sensation, giving me the idea as if they had been frostbitten. I dare say there is little the matter with me."

Colonel B-looks no more than his age, is well developed, muscular, but by no means fat. 'Tongue clean. Pulse seventytwo, soft, feeble. Heart's action normal, but weak; no bruit; no dyspncen.

Fingers of both hands, especially those of the right, are pale and cold ; the right little finger, from its point to its middle, feels cold as ice, and its ungual phalanx is blue-looks as if dead; under the tops of each nail, and extending across, there is a purple line about one-tenth of an inch in breadth.

No sign of inflammatory action is visible on either dorsal or palmar aspect of tho hands, and the thumbs are natural; none of the fingers are altered in shape, nor are they destitute of sense, except the last phalanx of the right little finger.

The ears are much colder than natural, have a mottled appearance, and exhibit on the outer and posterior part of each helix a number of echymosed patches.

I told Colonel B — his symptoms indicated great want of power as regards the circulation; that he was not to look upon them as trivial, but to watch them. I advised him to live more generously than usual, and to drink a pint of port, at least, after dinner. The fingers and eas s to be rubbed morning and evening with turpentine liniment, and covered with cotton wool; all cold ablutions to be discontinued.

Aug. 14th. - He tells me his fingers are still subject to become cold and numb on getting out of bed, and that it is some hours before circulation is established and warmth restored. They look very much better, except the right little one, the lower half of which is evidently dead; the point has become black and shrivelled-is mortified, in fact. I observe ecchymosed patches on the dorsal surfaces of two or three fingers similar to those on the ears. The ears are better; no increase of discoloration, and less painful to the touch; pulse 72, weak; bowels regular; urine healthy; appetite good. To continue treatment, and to take fifteen drops of turpentine three times a day on a piece of sugar.
15th.-Better; little finger more shrivelled.

16th. - Has passed a sleepless night, having been kept awake by severe and constant burning pain in the feet and toes; the feet are pale, cold, and clammy, the extremities of the toes being bluish and tender to the touch ; the fingers, except the little one, are well, and the ears are nearly so. To keep in bed, have the feet well rubbed with a dry warm towel, then with the turpentine liniment, and afterwards to be wrapped in cotton-wool. To take thirty drops of turpentine, and with each dose one-sixth of the following mixture :- Sulphate of quinine, twelve grains; chlorate of potash, one drachm and a half; syrup of ginger, six drachms; camphor mixture, to eight ounces. To take two of the following pills at bedime :Extract of hyoscyamus and extract of conium, of each twelve grains; camphor, six grains : make six pills.

17th.--Passed a better night ; feet warmer, toes less painful. Nothing, he says, annoys him but his little finger, which is dry, black, and cold as marble; on tapping the table with it, it sounds as if it were made of stone; the line of separation is beginning to show itself, but is by no means distinct. Continue treatment.

18th, - Last night he felt his feet so much better, that he left his room, and played two or three games at billiards. This morning he finds his feet better, and has passed a tolerable night; thought the exercise of last night did him good. No change in appearance of finger.

$19 \mathrm{th}$. - Feet well ; out walking before breakfast.

2lst.-Feeling that the separation of the dead portion of the little finger from the living would prove tedions, and having never seen a similar case, I advised Col. B— to have another opinion; and with that view he went to Leeds, and consulted Mr. Samuel Hey. This gentleman examined him curefully, advised that the finger should not be meddled with, recom. mended the addition of citrate of iron to his quinine mixture, the discontinuance of the stimulating embrocation, fearing it might induce excessive action in a part already deficient in vitality, but to keep the finger warm. In his note to me he asks the question, "What is the cause of gangrene here?-is it purpura, or diseased bloodvessels?"

24th. - The skin of the fingers and ears, underneath which patches of ecchymosis were observed, has desquamated, leaving healthy cuticle. The line of demarcation is now distinct, but there is no appearance of inflammation about it, no discharge, no smell.

Sept. 2nd. - I was sent for this morning in consequence of Col. B- having suffered during most of the night from a severe and constant burning pain in the second toes, the ends of which and underneatih the nails look bruised. He cannot bear to hang the feet down for above a few seconds, and dreads the slightest pressure. He looks anxious, and fears that the toes will mortify like the finger. On pressing the ball of the foot, or any part of the great toe, pain is occasioned; the feet are natural in appearance and temperature. As the treatment employed during his former attack proved successful, I had again recourse to it; adding an opiate at bedtime, with a little colchicum, as I began to think that the symptoms bore some resemblance to rbeumatism.

4th and 5th.- Symptoms somewhat improved.

6 th. - Passed a bad night; pain in toes on the increase. I therefore again recommended a consultation with $\mathrm{Mr}$. Hey, which I was fortunately able to attend. After a careful ex amination, Mr. Hey expressed his opinion that the causucs mal was to be found in the diseased condition of the bloodvessels, with a tendency to inflammation of the fibrous tissues. He had seen two similar cases, and thought it not improbable that the second toes might sphacelate. We agreed to try the effects of painting the balls of the feet and toes with tincture of the muriate of iron, and to give the following mixture:-Citrate of iron and quinine, one drachm; iodide of potash, sixteen grains; bicarbonate of potash, a drachm and a half; infusion of quassia to eight ounces: one-sixth three times a day. The soothing pills to be continued, and the feet to be kept in wool.

7th.-The patient had a better night; pain moderate.

9th. - Very much better; has had no pain in feet, and can bear firm pressure on the toes.

10th.-Perfectly well. To discontinue the application of the tincture of iron.

12th. - With the exception of the finger, the patient is quite well, and intends leaving to-morrow. The pulse is stronger, and the circulation in the extremities is free and natural There is no attempt in the finger at separation of the dead part from the living, and I fear it may be months before that is effected. I impressed upon Col. B- the necessity of keeping his hands and feet warm and dry, and of avoiding ex 